\title{
Effect of body position on gastric emptying in the neonate
}

\author{
VICTOR Y. H. YU \\ From the Department of Paediatrics, University of Oxford, John Radcliffe Hospital
}

Yu, V. Y. H. (1975). Archives of Disease in Childhood, 50, 500. Effect of body position on gastric emptying in the neonate. The effect of body position on gastric emptying was investigated in 48 neonates. The rate of gastric emptying is the same for healthy term, preterm, and small-for-dates infants. Infants with respiratory distress syndrome have delayed gastric emptying and a high incidence of abdominal distension and pooling of feeds in the stomach in the supine position. The stomach empties more rapidly in the prone and right lateral positions than in the supine and left lateral positions.

These findings indicate that the prone or right lateral positions are to be preferred for nursing neonates, especially those in whom intolerance to the volume of feeds is likely to be a problem. Supine or left lateral positions have little merit in helping gastric emptying and should not be used routinely in hospital nurseries.

The optimum sleeping position of the neonate has still to be determined. Paediatric nurseries in the United States favour the prone position, but in Europe, the Near East and Far East, the supine position is used (Brackbill, Douthitt, and West, 1973). The reasons for preferring the supine or prone positions have not been clearly expressed and seem to be based on custom rather than reason. As Gellis (1974) pointed out, comparisons between positioning the infant on left or right sides with the other positions have not been made. Research on the physiological and behavioural effects of body position in the neonate is required to justify the recommendation of one position rather than the other.

In a low birthweight or sick neonate, this consideration may be particularly vital as the disturbance necessitated by feeding, even with gavage, and the subsequent distension of the stomach can compromise cardiorespiratory function (Wilkinson and $\mathrm{Yu}, 1974$ ) or lead to inhalation pneumonia (Wharton and Bower, 1965). Though early feeding of low birthweight infants is now an established routine in most special-care nurseries (Davies et al., 1972), the success of this in a group of high-risk neonates depends not only on the amount, frequency, and method with which feeds are given but

Received 2 December 1974. probably also on the management of the neonates between feeds. Body position may be of considerable importance in this connexion no matter how carefully the feed is given.

In this study, the rate of gastric emptying in healthy term, preterm, and small-for-dates (SFD) infants and infants with idopathic respiratory distress syndrome (RDS) is related to the sleeping position of the infant.

\section{Patients and methods}

Forty-eight infants born in the John Radcliffe Hospital, Oxford, were studied. 12 were term infants admitted to the special-care nursery for short periods of observation but who subsequently proved to be well. 12 were healthy preterm infants, born before 37 weeks' gestation with birthweights appropriate for gestational age. 12 were SFD infants, those whose weight was below the 5th centile for gestational age and sex according to the data of Thomson, Billewicz, and Hytten (1968). The remaining 12 infants had classical clinical and radiological evidence of RDS.

All the infants studied were being fed in the specialcare nursery routinely via indwelling polyvinyl nasogastric tubes (Bardic No. 5 French) every 2 hours. The method of serial test-meals used in adults (Hunt, 1951) has been modified for study of gastric emptying in the newborn (Husband and Husband, 1969). The stomach was initially washed out with water so that it was free of large curds. Test-meals were given $1 \frac{1}{2}$ hours 
after the last feed in the volume of $7 \mathrm{ml} / \mathrm{kg}$ over a period of 3-4 minutes. After an interval of 30 minutes, the gastric contents were aspirated. The stomach was then washed out with $20 \mathrm{ml}$ water to recover any remaining contents. The test-meals were $10 \%$ glucose $(556 \mathrm{mOsm} / \mathrm{kg}$ ) with added phenol-red, $0.24 \mathrm{mg} / 100 \mathrm{ml}$. The latter acts as a marker as it is not absorbed from the stomach and has no effect on gastric emptying (Hunt, 1956). The volume of the original test-meal which is still in the stomach can then be calculated from the total gastric content recovered, independent of added gastric secretions and saliva (Hunt and Knox, 1962). The concentration of phenol-red was measured by spectrophotometry (wave length $550 \gamma$ ) in the original test-meal (a), the gastric aspirate at 30 minutes (b), and the washout (c).

\section{EXAMPLE}

$\begin{array}{lcc} & \text { Volume }(\mathrm{ml}) & \text { Optical density } \\ \text { (a) Original test-meal } & 21 \cdot 0 & 0.28 \\ \text { (b) Aspirate at } 30 \mathrm{~min} & 7 \cdot 5 & 0.25 \\ \text { (c) Washout } & 20.0 & 0.02\end{array}$

Vol. of original meal in (b) $=(7 \cdot 5 \times 0 \cdot 25) / 0 \cdot 28=6 \cdot 7 \mathrm{ml}$ Vol. of original meal in $(c)=(20 \times 0 \cdot 02) / 0 \cdot 28=1.4 \mathrm{ml}$ Vol. of original meal remaining in stomach at $30 \mathrm{~min}$ $=8 \cdot 1 \mathrm{ml}$

$\%$ retention of original meal at $30 \mathrm{~min}=(8 \cdot 1 / 21)$ $\times 100=38 \cdot 6 \%$.

Each infant was given a test-meal in two different positions during the first 24 hours of life. Three study groups were utilized:(1) supine and prone positions, (2) supine and left lateral positions, and (3) supine and right lateral positions. The infants were assigned to each of the study groups by random selection. All were maintained in the required position for at least 3 hours before and for 30 minutes after the feed. The sequence in which the infants were studied in supine or one of the other positions was alternated.

Infants with RDS were not studied in the prone position because this rendered routine clinical and nursing observations difficult. It is not known whether catheterization of umbilical vessels has any adverse effects on intestinal motility or gastric emptying. Since all the infants with RDS studied in the first 24 hours of life had umbilical arterial and venous catheters in place, the rate of gastric emptying was further compared in 12 infants before and after the umbilical catheters were removed.

\section{Results}

Table I shows the values for birthweight, gestation, and postnatal age in the infants studied. The subgroups shown in Table II were analysed to see whether the changes observed for gastric emptying were influenced by birthweight, maturity, or postnatal age when studied.

The results of the test-meals given in the supine position are shown in the Fig. A mean of $41.5 \%$

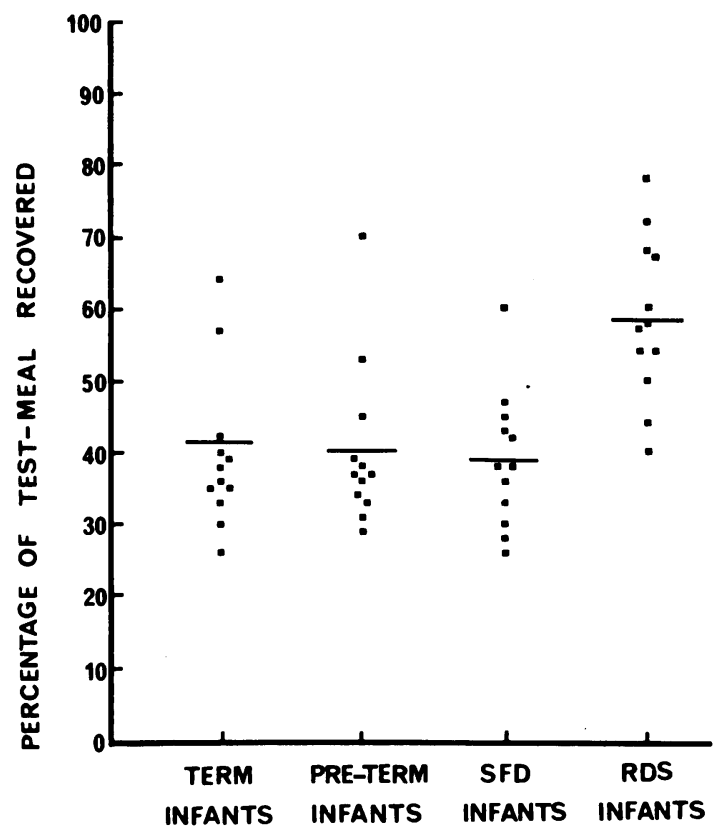

FIG.-Percentage of test-meal recovered 30 minutes after feed in healthy term, preterm, and SFD infants, and those with RDS. Horizontal bar shows mean value for each group.

TABLE I

Characteristics of infants studied

\begin{tabular}{|c|c|c|c|c|c|c|}
\hline \multirow{2}{*}{ Subjects } & \multirow{2}{*}{$\begin{array}{c}\text { No. } \\
\text { of } \\
\text { infants }\end{array}$} & \multicolumn{2}{|c|}{ Birthweight } & \multicolumn{2}{|c|}{ Gestation } & \multirow{2}{*}{$\begin{array}{c}\begin{array}{c}\text { Postnatal age } \\
\text { when studied in } \\
\text { supine position }\end{array} \\
\text { Mean } \pm \text { SEM }\end{array}$} \\
\hline & & Mean \pm SEM & Range & Mean \pm SEM & Range & \\
\hline $\begin{array}{l}\text { Term infants } \\
\text { Preterm infants } \\
\text { Small-for-dates infants } \\
\text { Infants with RDS }\end{array}$ & $\begin{array}{l}12 \\
12 \\
12 \\
12\end{array}$ & $\begin{array}{l}3614 \pm 149 \\
2338 \pm 127 \\
2228 \pm 51 \\
2555 \pm 154\end{array}$ & $\begin{array}{l}2910-4480 \\
1430-2980 \\
2005-2480 \\
1790-3460\end{array}$ & $\begin{array}{l}39 \cdot 5 \pm 0 \cdot 1 \\
35 \cdot 3 \pm 0 \cdot 5 \\
37 \cdot 7 \pm 0 \cdot 3 \\
35 \cdot 8 \pm 0.8\end{array}$ & $\begin{array}{l}39-40 \\
33-37 \\
36-40 \\
31-39\end{array}$ & $\begin{array}{l}12 \cdot 3 \pm 1 \cdot 4 \\
13 \cdot 3 \pm 1 \cdot 5 \\
12 \cdot 6 \pm 1 \cdot 7 \\
11 \cdot 0 \pm 2 \cdot 0\end{array}$ \\
\hline
\end{tabular}


TABLE II

Characteristics of infants in different subgroups

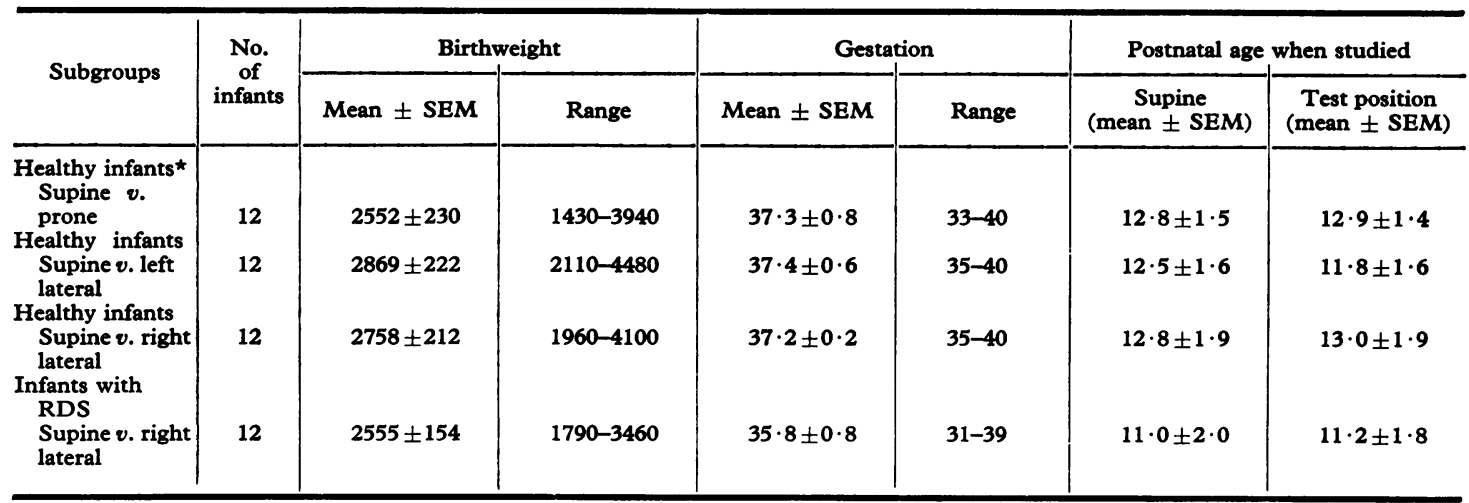

*Healthy infants include 4 term, 4 preterm, and 4 SFD infants who are clinically well.

(SEM $\pm 3 \cdot 3$ ) of the original test-meal was recovered in 12 term infants, $40 \cdot 2 \%$ (SEM $\pm 3 \cdot 1$ ) in 12 preterm infants, and $38.8 \%$ (SEM $\pm 2 \cdot 6$ ) in $12 \mathrm{SFD}$ infants. The differences are not significant by Student's ' $t$ ' test. In contrast, the mean for the test-meal recovered in infants with RDS was $58 \cdot 3 \%(S E M \pm 3 \cdot 2)$. The differences between this and the other 3 groups of healthy infants are significant $(P<0.001)$. Furthermore, 5 of the 12 infants with RDS developed abdominal distension and required temporary cessation of oral feeds in the first $\mathbf{4 8}$ hours of life while nursed in supine position.

The effect of body position on gastric emptying is shown in Table III. In the healthy infant group, comprised of clinically well term, preterm, and SFD infants, there was less retention of the test-meal 30 minutes after the feed in the prone position compared with the supine $(P<0.05$ by the ' $t$ ' test for pairs). No difference was observed between infants in the supine position and those on their left sides. Comparison between right lateral and supine positions showed less retention in the former position both in clinically well infants $(P<0.05)$ and in those with RDS $(P<0.01)$. Results of 4 studies in infants with RDS positioned on their left sides showed a mean of $77 \%$ recovery of the test-meals $\mathbf{3 0}$ minutes after feeds, compared with $60 \%$ when tested in supine position. This, together with the clinical impression in the nursery that infants with RDS while nursed on their left sides tend to develop more abdominal distension and pool their feeds in the stomach, made us reluctant to continue to study ill infants in the left lateral position.

Gastric emptying studies were carried out in $\mathbf{1 2}$ infants with RDS immediately before the removal of umbilical arterial and venous catheters which had been in situ for between 10 and 96 hours. Results showed $42 \cdot 9 \%(S E M \pm 3 \cdot 3)$ retention in

TABLE III

Gastric emptying in different body positions

\begin{tabular}{|c|c|c|c|c|}
\hline \multirow{2}{*}{ Subgroups } & \multirow{2}{*}{ No. of infants } & \multicolumn{2}{|c|}{ Percentage retention of feeds in $30 \mathrm{~min}$} & \multirow{2}{*}{ Significance level } \\
\hline & & Supine & Test position & \\
\hline $\begin{array}{l}\text { Healthy infants } \\
\text { Supine } v \text {. prone } \\
\text { Healthy infants } \\
\text { Supine } v \text {. left lateral } \\
\text { Healthy infants } \\
\text { Supine } v \text {. right lateral } \\
\text { Infants with RDS } \\
\text { Supine } v \text {. right lateral }\end{array}$ & $\begin{array}{l}12 \\
12 \\
12 \\
12\end{array}$ & $\begin{array}{l}39 \cdot 0 \pm 2 \cdot 8^{\star} \\
40 \cdot 3 \pm 2 \cdot 9 \\
39 \cdot 3 \pm 3 \cdot 0 \\
58 \cdot 3 \pm 3 \cdot 2\end{array}$ & $\begin{array}{l}33 \cdot 3 \pm 2 \cdot 9 \\
41 \cdot 1 \pm 2 \cdot 1 \\
33 \cdot 9 \pm 3 \cdot 8 \\
46 \cdot 6 \pm 3 \cdot 6\end{array}$ & $\begin{array}{c}\mathrm{P}<0.05 \\
\text { NS } \\
\mathrm{P}<0.05 \\
\mathrm{P}<0.01\end{array}$ \\
\hline
\end{tabular}

*Mean \pm SEM. 
the stomach 30 minutes after the feed. Test-meals were repeated 6-8 hours after the umbilical catheters were removed and the results showed $39.2 \%$ $(\mathrm{SEM} \pm 3 \cdot 2)$ retention. The difference is not significant and it is unlikely that umbilical catheterization by itself has any effect on gastric emptying.

There was no correlation observed in rate of gastric emptying with the following variables: (1) birthweight of infant, (2) gestation, (3) postnatal age when studied.

\section{Discussion}

All earlier studies of gastric emptying in the newborn were by means of radiological techniques (Smith and LeWald, 1915; De Buys and Henriques, 1918; Bouslog et al., 1935; Henderson, 1942; Miller and Ostrum, 1945; Schell, Karelitz, and Epstein, 1963). Disadvantages include the hazards of radiation which limited comparison within subjects of the emptying rate in different situations. The volume of a barium meal may be steadily increased by gastric secretions themselves (Liebowitz et al., 1957) and hyperosmolar radio-opaque meals were shown to inhibit gastric peristalsis and stop emptying (Shay and Gershon-Cohen, 1934). Differences in character and quantity of barium in the test-meals were also thought to be sources of errors (Silverio, 1964). Vendel's (1948) nonradiological study of gastric emptying in infants involved aspiration of gastric contents at regular intervals after a feed, measuring the volume, and returning the contents into the stomach. However, the quantity of added gastric secretion and saliva was unknown and it was not possible to avoid stimulation of peristalsis with the changes in volume during repeated aspirations. The present method of study is safe and reasonably reliable and causes no evident clinical disturbance to the infants or to the nursing routine. It is not the aim of this study to determine the end-point of gastric emptying but only the comparison of the rate of emptying in the 30 minutes after the testmeal. Clinical impressions on the degree of pooling of milk by the time of the next feed in these infants who are fed 2-hourly nevertheless appeared to be consistent with the results obtained in this study.

Schell et al., (1963), whose work was done exclusively on preterm infants, found no correlation of gastric emptying time with either postnatal age of the infants or with their weights. The present observations confirm this, and similar rates of gastric emptying were obtained in term, preterm, and SFD infants.

Infants with RDS, however, were found to have delayed gastric emptying. Hypoxaemia is known to prolong gastric emptying time in both animals (Van Liere, Crisler, and Robinson, 1933) and human subjects (Van Liere, Lough, and Sleeth, 1936). Another explanation may be that infants with respiratory distress accumulate excessive air in the stomach which may influence gastric emptying. Infants are notoriously aerophagic (Smith and LeWald, 1915; Henderson, 1942; Miller and Ostrum, 1945), especially while crying, yawning, or bottle-feeding, and it is likely that with the increased respiratory effort in RDS, the stomach can easily be filled with air.

Smith and LeWald (1915) first stressed the importance of body position of the newborn as regards gastric functioning. More specifically, a study in older infants and children (De Buys and Henriques, 1918) showed that barium emptied from the stomach faster in the right lateral than in other positions. We also have found gastric emptying to be more rapid in right lateral than supine or left lateral positions but similar to that in the prone position. Miller and Ostrum (1945) reported that gaseous distension of the gastrointestinal tract in infants can be relieved by placement for several hours in the semirecumbent prone position and recommended the procedure as a prerequisite for radiological investigations in suspected hypertrophic pyloric stenosis in infants. In a recent study (Brackbill et al., 1973), it was found that when prone, infants sleep more, cry less, and have more regular respirations, all of which may result in less air actually introduced into the stomach while in this position.

A study of fluid-gas relations in the stomach in young infants in different positions (Hood, 1964) showed that when supine, fluid accumulates in the fundus which is the most dependent position of the stomach; and the air bubble rises to the highest part, the pyloric antrum. The fluid-filled fundus acts as a barrier to prevent eructation and hence the supine position may predispose to regurgitation and inhalation. Retention of feeds occurs as a result of air accumulating at the pyloric end. With the passage of this swallowed air into the small intestine, gaseous distention of the duodenum can further inhibit gastric emptying (Miller and Ostrum, 1945).

Thus it is desirable to limit the amount of swallowed air and to confine what is ingested to the fundus to facilitate its return. Gastric emptying is quicker after tube-feeding (Hunt, 1956) because it was thought that the large influx of air into the stomach, as with bottle feeding, does not occur (Hood, 1964). Nevertheless, gaseous distension of the stomach often occurs in tube-fed infants, particularly those ill with respiratory distress and it 
may be advisable to perform routine gastric aspiration before each feed or to adopt the practice of leaving the indwelling nasogastric tube unspigotted and open to the atmosphere between feeds. It is probably as necessary to 'burp' infants after tubefeeds as after bottle-feeds.

Most of the discussion about the relative merits of nursing infants prone or supine have been concerned with motor and sensory effects. The supine position favours the development of sensory perception particularly of the eyes but at the expense of the motor aspect such as control of the neck muscles (British Medical Journal, 1961). In Europe, the supine position is more popular probably because of fears that the prone infant might suffocate with his face in regurgitated milk or in a pillow. However, prone infants were thought to be more contented (Brackbill et al., 1973), which in turn can help the development of a good mother-child relationship (Bell, 1971). This study gives a further reason why the prone position, or alternatively the right lateral position, should be used for nursing neonates.

I thank Professor J. P. M. Tizard and Dr. David Baum for valuable suggestions and for review of the manuscript.

\section{REFERENCES}

Bell, R. Q. (1971). Stimulus control of parent or caretaker behaviour by offspring. Developmental Psychology, 4, 63.

Bouslog, J. S., Cunningham, T. D., Hanner, J. P., Walton, J. B., and Waltz, H. D. (1935). Roentgenologic studies of the infant's gastrointestinal tract. Fournal of Pediatrics, 6, 234.

Brackbill, Y., Douthitt, T. C., and West, H. (1973). Psychophysiologic effects in the neonate of prone versus supine placement. Fournal of Pediatrics, 82, 82.

British Medical fournal (1961). (Leader). Prone or supine?, 1, 1304.

Davies, P. A., Robinson, R. J., Scopes, J. W., Tizard, J. P. M., and Wigglesworth, J. S. (1972). Medical Care of Newborn Babies, p. 96. Spastics International Medical Publications. London and Philadelphia.

De Buys, L. R., and Henriques, A. (1918). Effect of body posture on the position and emptying time of the stomach. American fournal of Diseases of Children, 15, 190.
Gellis, S. S. (ed.) (1974). Year Book of Pediatrics, p. 26. Year Book Medical Publishers, Chicago.

Henderson, S. G. (1942). The gastrointestinal tract in the healthy newborn infant. American fournal of Roentgenology, 48, 302.

Hood, J. H. (1964). Effect of posture on the amount and distribution of gas in the intestinal tract of infants and young children. Lancet, $2,107$.

Hunt, J. N. (1951). The secretory pattern of the stomach in man. Fournal of Physiology, 113, 169.

Hunt, J. N. (1956). Some properties of an alimentary osmoreceptor mechanism. Fournal of Physiology, 132, 267.

Hunt, J. N., and Knox, M. T. (1962). The regulation of gastric emptying of meals containing citric acid and salts of citric acid. Fournal of Physiology, 163, 34.

Husband, J., and Husband, P. (1969). Gastric emptying of water and glucose solutions in the newborn. Lancet, 2, 409.

Liebowitz, D., Zippin, C., Shreeve, W. H., and Kaufman, J. S. (1957). A comparison of the estimation of gastric retention by radiologic and direct quantitative methods. Gastroenterology, 33,621 .

Miller, R. F., and Ostrum, H. W. (1945). Hypertrophic pyloric stenosis in infants. American fournal of Roentgenology, 54, 17.

Schell, N. B., Karelitz, S., and Epstein, B. S. (1963). Radiographic study of gastric emptying in premature infants. Fournal of Pediatrics, 62, 342.

Shay, H., and Gershon-Cohen, J. (1934). Experimental studies in gastric physiology in man. Surgery, Gynecology and Obstetrics, 58, 935.

Silverio, J. (1964). Gastric emptying time in the newborn and the nursling. American fournal of the Medical Sciences, 247, 732.

Smith, C. H., and LeWald, L. T. (1915). The influence of posture on digestion in infancy. American fournal of Diseases of Children, 9, 261.

Thomson, A. M., Billewicz, W. Z., and Hytten, F. E. (1968). The assessment of fetal growth. Fournal of Obstetrics and Gynaecology of the British Commonwealth, 75, 903.

Van Liere, E. J., Crisler, G., and Robinson, D. (1933). Effect of anoxemia on the emptying time of the stomach. Archives of Internal Medicine, 51, 796.

Van Liere, E. J., Lough, D. H., and Sleeth, C. K. (1936). Effect of anoxemia on the emptying time of the human stomach. Archives of Internal Medicine, 58, 130.

Vendel, S. (1948). The principle of evacuation of the stomach in infants and prematures. Acta Paediatrica, 35, (Suppl. 1), 178.

Wharton, B. A., and Bower, B. D. (1965). Immediate or later feeding for premature babies ? A controlled trail. Lancet, 2, 969.

Wilkinson, A., and Yu, V. Y. H. (1974). Immediate effects of feeding on blood-gases and some cardiorespiratory functions in ill newborn infants. Lancet, 1, 1083.

Correspondence to Dr. V. Y. H. Yu, Department of Paediatrics, University of Oxford, John Radcliffe Hospital, Headington, Oxford OX3 9DU. 